\title{
MAURIZIO PINTORE, TUTTO QUI..., PRINTARTEDIZIONI, NOCERA SUPERIORE (SA) 2019, PP. 247
}

\author{
Antonio Scocozza \\ Università degli Studi di Salerno \\ Universidad Católica de Colombia
}

DOI: http://dx.doi.org/10.14718/CulturaLatinoam.2019.30.2.14

Sentado frente al escritorio del doctor Maurizio Pintore, pude hojear Tutto qui... Esa mañana, mi ahijado Graziano, me había acompañado al hospital de Oliveto Citra (SA) a la División de Terapia del Dolor, pues desde hace un mes, un dolor en la parte baja de la cadera no me abandonaba. De repente, me sentía viejo, casi no podía caminar, y además la idea de entrar en la división de terapia del dolor me asustaba ya que, por lo general, entran pacientes con traumas y enfermedades graves y los médicos se esmeran para acompañarlos sin sufrimientos en momentos que pueden ser los últimos de esta experiencia terrenal. Mientras pensaba en estas cosas y hojeaba Tutto qui... entra un médico alto, flaco, simpático y muy seguro de sí, mi ahijado me lo presentó: "Es el doctor Maurizio Pintore, director de la División", "Mucho gusto - contesté - soy Antonio Scocozza y tengo un tremendo dolor en la cadera que no me deja casi ni respirar”. “ $¡ A h !$ Usted es el profesor del que tanto me habla Graziano" y estreché su mano con simpatía y esperanza. “¿Estaba leyendo mi libro? - me dijo - Es mi primer libro, casi tengo pena pero, necesitaba escribirlo. Si me permite se lo regalo”. Inmediatamente, después de haber escrito 
una linda dedicatoria, me lo entregó. Leyó mi historia clínica y me dijo: "Le aplico una inyección epidural para tratar de aliviarlo por el momento, me ha dicho Graziano que usted viaja mañana a Bogotá y quiero que vaya en buenas condiciones. De usted me habló también el director del hospital de Eboli, Mario Minervini, compartimos varios amigos. Por ahora no puedo hacer mucho más, cuando regrese resolveremos definitivamente el problema". Con mucha sencillez y sin que advirtiera ningún dolor me inyectó en la columna, me saludó con gran simpatía y regresó a sus pacientes. Durante todo el vuelo a Bogotá pude leer el libro: sencillo, simpático, emocionante, una recreación del espíritu. Diez horas que pasaron sin que me diera cuenta. Cerré la última página con un suspiro y una sonrisa y me puse a pensar. En pequeños y breves cuentos me presentaba su vida, y sobre todo su entorno de vida, la técnica del cuento breve parecía conocerla muy bien pero él era medico y entonces cómo podía dar esas pinceladas de prosas que describen ocasiones irrepetibles, palabras que hacen revivir momentos inolvidables, momentos sencillos de todos los días, así como momentos significativos, de esos que marcan la vida de un hombre. Todo filtrado, sin saberlo él y sin que lo sepan sus lectores, por una vida dedicada a la lucha del dolor de los demás. El dolor físico es la experiencia vital más cercana a la muerte, mejor dicho, es a veces el inicio del camino que acaba con todos los caminos. El dolor físico te hace doler también el alma y el corazón, te asusta, te "achicopala", te hace entrar en un túnel en donde no se ve ninguna luz y, finalmente, cuando no te da tregua, te hace desear la muerte. No tienes armas para luchar, no sabes qué hacer, puedes solo soportar y esperar, y a tu lado solo un guerrero vestido de blanco, Maurizio Pintore, con sus agujas, sus medicinas, su inteligencia, su ciencia, pero, sobre todo, su corazón tratando de sacarte de ese laberinto en donde tú te estás perdiendo. Una sonrisa cuando el paciente sonríe, una lágrima escondida cuando siente que toda su ciencia, toda su pasión no puede nadar contra la ineluctabilidad de la muerte. Su alma, es alma de guerrero, se llena de los dolores de todos sus pacientes y no encuentra donde poderse "lavar" de esos dolores para poder atacar el próximo y luego otro. Cuántas batallas, cuántas sonrisas, cuántas lágrimas, cuánta desesperación y..., entonces la escritura. La escritura que te libera, te lava, te limpia, te ayuda, te objetiviza, la escritura que te permite vivir día tras día con la esperanza de poderlo contar, y yo, pequeño artesano de la cultura, aliviado de un dolor, no tan grave, pero que no me permitía realizar mis oficios, estoy aquí leyendo y empapándome de la experiencia vital de Maurizio. Ustedes dirán que su trabajo literario no es directamente homogéneo a los contenidos de 
esta revista, pero yo, en "Tutto qui...", encontré un cuento que habla de un emigrante italiano a Venezuela, claro está, no la Venezuela de hoy, desesperada y hambrienta, de la cual se puede sólo escapar; la Venezuela del segundo Boom económico de los años 70 y 80 . En ese cuento me pareció ver miles de jóvenes italianos encontrados en una Caracas de oro que ya no existe. Recordé que yo también fui un joven profesor emigrante, que mis hijos y mis amigos son emigrantes, recordé con el cuento de Maurizio una parte de mi juventud. Un cuento breve, tan sólo dos páginas, que me encantó y me hizo reflexionar sobre la gran vocación literaria de Maurizio. No diré más, quiero que ustedes lo lean y yo me voy a permitir proponérselo en mi traducción personal, esperando que mi español esté a la altura de su italiano. Los lectores de esta revista me perdonarán si después de 20 años me robo pocas páginas para compartir con ustedes esta nueva y emocionante amistad con Maurizio y con sus escritos. Pero este cuento me parece un capítulo más del gran corazón de Venezuela hacia los emigrantes de todos los países del mundo. Que Dios salve Venezuela.

P.S. Mi cadera está mucho mejor.

\section{TERMOCHAQUETA en Tutto qui..., cit. pp. 165-167.}

La vida está hecha de oportunidades, trenes que pasan veloces y sobre los cuales suben sólo los que tienen en el alma el deseo de no quedar en la banca...

Enzo Trabucco, alias Termochaqueta, tiene una colocación sui generis en los recuerdos de los amigos de Torrione (barrio de Salerno, n.d.t.) de los años 70 y principios de los 80 , es un pequeño ejemplo de self made man, podría ser esta una posible síntesis de su persona, el recuerdo no me sugiere otra cosa. Enzo había nacido adulto, ya hombre. Pienso que nunca tuvo una adolescencia. Cualquiera que hubiese hechado una mirada al grupito de mis amigos aparcados delante del Bar Tuo, hubiera pensado que Enzo era nuestro tío o algo similar. Siempre centrado, distinguido, serio, silencioso, inmóvil o con movimientos y gestualidad nunca casuales. Un cigarrillo siempre entre los dedos, fumar era un ritual con un estilo digno de Humphrey Bogart, con una mirada sigilosa para que el humo no invadiera sus ojos, nos miraba con desencanto, nosotros demasiado buevones para él. De todas maneras, el elemento clou de su figura era la Termochaqueta, una chaqueta de pana negra, de dos botones, pero siembre abierta, y generalmente con una camisa azul claro, jamás la corbata. Llevaba prácticamente esa chaqueta 12 meses al año, no importaba la estación ni los cambios meteorológicos. Me imagino que él la lavaba de 
noche para tenerla limpia al otro día. La razón por la que llevaba siempre esa chaqueta creo que estaba bien establecida por la respuesta constante que Enzo daba cuando le pedían una explicación: "Tengo esta, una como esta y si no fuera por esta, no tuviera ninguna". Segundo de tres hermanos varones, de una familia humilde pero altamente honrada, Enzo a veces comentaba la vergüenza que sentía cuando regresaba a su casa por la mañana hacia las 5:00, después de una "noche brava" con nosotros y se cruzaba en la puerta de la casa con la mirada de su papá, un albañil, que iba a trabajar. Mirándolo a los ojos el padre le sentenciaba, indignado: “¡Avergüénzate!”. Recuerdo vivamente de su personalidad la dignidad y discreción que tenía en toda situación, a veces con mis amigos nos mirábamos a los ojos con mucha complicidad, entonces alguien inventaba una excusa para proponer y brindar una pizza, Enzo declinaba la invitación: "perdonen no voy a venir, estoy todavía lleno, no he acabado de digerir el almuerzo". Inútil decir que hacía con esmero cualquier trabajo: se las arreglaba de cualquier manera, en cualquier modo. Esto hasta el fatídico cambio. La vida, clásicamente, está a merced del azar. La ocasión que dio un cambio determinante a su destino fue el regreso a Salerno de sus familiares que habían emigrado a Venezuela. Después de una breve estadía de sus primos venezolanos, de los cuales recuerdo uno que hacía enloquecer a todas nuestras amigas por la forma de bailar, regresó con ellos al país suramericano a pasar unas breves vacaciones. Total, no volvimos a saber de Enzo por lo menos en cuatro o cinco años. Sus hermanos nos contaron que después de un duro aprendizaje en varios trabajos, había al fin "triunfado", ingresando en una cadena de empresas petroleras en las cuales se ocupaba de mediación y de contratos. Como se dice comúnmente, "hizo billete". Un día supimos de su regreso a Salerno para visitar a sus padres, lo esperamos con emoción y curiosidad, como si hubiera regresado de la luna, fue un remake muy caluroso. Él, excitado, quería comprar media Salerno, pero no tenía altivez, era el de siempre. La novedad simpática era la inserción, en nuestro dialecto, de alguna que otra palabra en español que se le escapaban. Con sencillez nos hacía solo entender que quería compensar de tantos sacrificios y tantas privaciones a su familia y a él mismo. Antes de que regresara a Suramérica, nos reunimos los amigos de siempre y jodimos un poco por la ciudad. Él siempre brindaba, yo lo miraba divertido, observando el continuo cambio de toda una variedad de chaquetas de moda y pensaba en su termochaqueta. Pensaba en cuando se reunía conmigo después del almuerzo en el Bar Tuo y me decía, jugando con una moneda de cincuenta liras entre los dedos: "Si tienes otra cincuenta liras, nos tomamos entre los dos una tacita de café". 